\title{
THE LATEST GENERATION OF EU SMART CITY PROJECTS: TURNING "CLEAN ENERGY FOR ALL" INTO "CLEAR BENEFITS FOR ALL"
}

\author{
Adriano BISELLO, Eurac Research - Institute for Renewable Energy; Italy \\ Daniele VETTORATO, Eurac Research - Institute for Renewable Energy; Italy
}

\begin{abstract}
The European Union is in the process of updating its energy policy and legislative framework under the motto "Clean Energy for All Europeans". This will facilitate the low carbon energy transition, make it fit for the 21st century, and delivering the EU's Paris Agreement commitments.

Besides expected climate-energy benefits, the EU narrative is introducing new elements to persuade citizens and stakeholders to change their perspective, shifting the general perception from mitigation costs to development opportunities. For example, impact assessment of the new directives estimated that they would generate 900,000 jobs and an increase of up to 1\% in EU GDP over the next decade. However, this is just one among several multiple benefits that could be gained thanks to the smart energy transition of cities and neighborhoods (e.g. increased value of refurbished properties, improved health and well-being, enhanced social cohesion, etc.)

Starting from this premise, the ongoing research will analyses 12 ongoing EU smart cities and communities projects started between 2014 and 2017, in order to investigate their capability in using the multiple benefits as an effective communication tool, or even including them among the key performance indicators to be used in the assessment phase.

In that respect, the Positive energy district concept that permeates the smart city approach of latest calls for funding provides, even more, an interesting nexus and testbed opportunity for EU ambitions. However, ongoing and future projects need to be understood not only as marketing devices for new energy efficient technologies but powerful tools requiring a radical change in management and planning of cities and urban life. In this way, positive energy districts including good habits and behaviors of urban citizens will provide equitable solutions and clear benefits for all.
\end{abstract}

\section{Keywords}

Smart city, positive energy district, energy community, multiple benefits, energy transition 


\section{Introduction}

Nowadays, half of the global population lives in urban areas and by 2050 up to $70 \%$ of the world's population will be living there.

It is therefore clear why the UN Agenda 2030 for Sustainable Development and the COP21 Paris Agreement recognize the pivotal role of cities as drivers of change and calls on them to rapidly reduce greenhouse gas emissions and adapting to climate change.

The European Union (EU) is also committed to achieving the targets posed by the two above-mentioned documents and making cities inclusive, safe, resilient and sustainable according to the Sustainable Development Goal 11.

Many ambitious EU cities already decided to set strict climate-energy goals and to test the implementation of highly integrated and highly efficient energy systems based on the exploitation of local renewable energy sources (RES). The so-called smart urban energy transition, as a consequence of the transposition into the practice of EU legislative package "Clean Energy for All Europeans" (European Commission, 2016) is also expected to deliver a wide range of non-energy benefits in the social, economic, and environmental areas.

As stated by Ürge-Vorsatz et al. (2016) "in the energy and climate change research and policy fields, the concept of "multiple benefits" (also termed "co-benefits", "multiple impacts", "non-energy benefits", etc.) has evolved as a field of analysis showing that the impacts of low-carbon energy transformations go hand-in-hand with many other societal and economic objectives".

In this sense, any innovation addressing energy consumption in the building sector - the largest single energy consumer in Europe - or changes in the energy market for better integration of RES in urban areas or enabling energy sharing by prosumers is expected to deliver substantial multiple benefits (Zambotti, Pezzutto and Bisello, 2019).

In particular, EU planners and designers are called to stimulate and enable the roll-out of visionary and holistic smart city projects aiming at increase energy performance of urban districts - including deep renovation of buildings in terms of technologies, processes and business models - while ensuring an increase in the overall quality of life of citizens and a better living environment.

This paper offers a first overview on a research path for the investigation of EU smart city projects under the multiple-benefits perspective, in order to foster the adoption of this assessment paradigm in the evaluation of their results and inclusion among key performance indicators (KPIs)

\section{European smart city projects}

\subsection{Evolution of the approach and goals}

Smart city is undoubtedly a sexy buzzword, used and abused in a wide range of contexts, from urban planning policies to advertisements of ICT companies.

Similarly, urban projects labeled as "smart city projects" widely differ. Within this blurry is it possible to identify some projects having recurrent characteristics and pursuing a coherent aim. Since 1984, multi-year funding programs have been developed by the European Union 
(EU) to support and foster research and technological development in the European Research Area. In the last decade, the European Union encouraged cross-sectorial urbanenergy renewal through specific funding calls, within the sixth and seventh European Research Framework Programme, also known as FP6 and FP7 and later thanks to Horizon 2020.

Such projects, implementing measures on new as well on existing urban districts, overcome the previous single-building approach. Benefits occurring in demonstration sites, in terms of improved energy performances, energy saved, or produced by RES and the tons of $\mathrm{CO} 2$ avoided, are widely known (Pol and Lippert, 2010). Moreover, they are used as the main examples to communicate the value of the project to the involved stakeholders, as well as to the general public. Aiming to demonstrate the feasibility of innovative solutions as well as cutting-edge approaches, such projects should involve research centers, universities, and partners from business and industry, and civil society organizations, in order to put into practice the quadruple helix innovation model. Moreover, for projects eligibility in this field, it is mandatory is the establishment of a temporary consortium of partners from various member and associate countries, and the identification of a pool of "demo cities" and some "follower" cities. In fact, having to be implemented into real-world urban settlements, the inclusion of local authorities is required. In some cases, the previous involvement of the city government into the Covenant of Majors is also a preliminary condition.

The pioneering initiative was the so-called "Concerto", between 2003 and 2008, funded by FP6 and FP7, with 28 accomplished sustainable energy districts projects, involving 58 cities and communities. The Concerto initiative has paved the way to the subsequent, and still ongoing, European Innovation Partnership - Smart Cities and Communities initiative (EIP SCC), which addresses the challenge of pursuing the smart energy transition of cities.

The novelty of the SCC approach lies in a more extensive integration of innovative energyefficient solutions with information and communication technologies which in fact shift the focus from the sustainable development approach to the smart-city concept. Additionally, more emphasis is placed on scalability and the replication potential of interventions. Under this calls, 12 projects have been financed, involving 36 Lighthouse cities and 42 Follower cities between the year 2014 and 2017. This set of projects is under consideration in this research.

The last evolutionary step of the EU smart city projects is represented by the recently funded projects answering the call SCC in the year 2018 and 2019. These projects will shift the focus from high-performance buildings and energy systems or net zero energy neighborhoods towards the positive energy district (PED) and the smart urban energy transition. A positive energy districts consist of several buildings (new, retrofitted or a combination of both) that actively manage their energy consumption and the energy flow between them and the wider energy system., having an annual positive energy balance. The positive balance is achieved thanks to the exploitation of local renewable energy sources RES, local storage, smart energy grids, demand-response systems, integrated energy management (electricity, heating, and cooling), co-design and user interaction (European Commission, 2018b).

The concept of positive energy district is something quite new, coming from the European Strategic Energy Technology Plan (SET-Plan) (European Commission, 2018a) which aims to accelerate the development and deployment of low-carbon technologies. The SET-Plan seeks to improve new technologies and bring down costs by coordinating national research efforts 
and helping to finance projects. The SET-Plan action 3.2 - Smart cities and communities focusses on PED, aiming to deliver at least 100 of them by 2050 (this target year has been recently revised to 2025), considering the interaction and integration between the buildings, the users and the larger urban and regional energy system.

Unfortunately having been started in 2018-2019, PED projects are in a too early stage to provide enough information or official results. In this sense, the paper considers SCC projects started between 2014 and 2018 the latest suitable set for investigation.

\subsection{The subset of investigated SCC projects}

Previous research on co-benefits and co-opportunities expected or claimed by EU smart and sustainable city projects has been done by (Bisello et al., 2017) and some of the main findings have been recalled in (Bisello and Vettorato, 2018). At that time, older Concerto and SCC projects have been considered. Figure 1 summarizes the most recurrent benefits; those mentioned by at least half of the projects have solid fill.

Numeber SSEDPs mentioning the co-benefit (Tot. $=36$ )

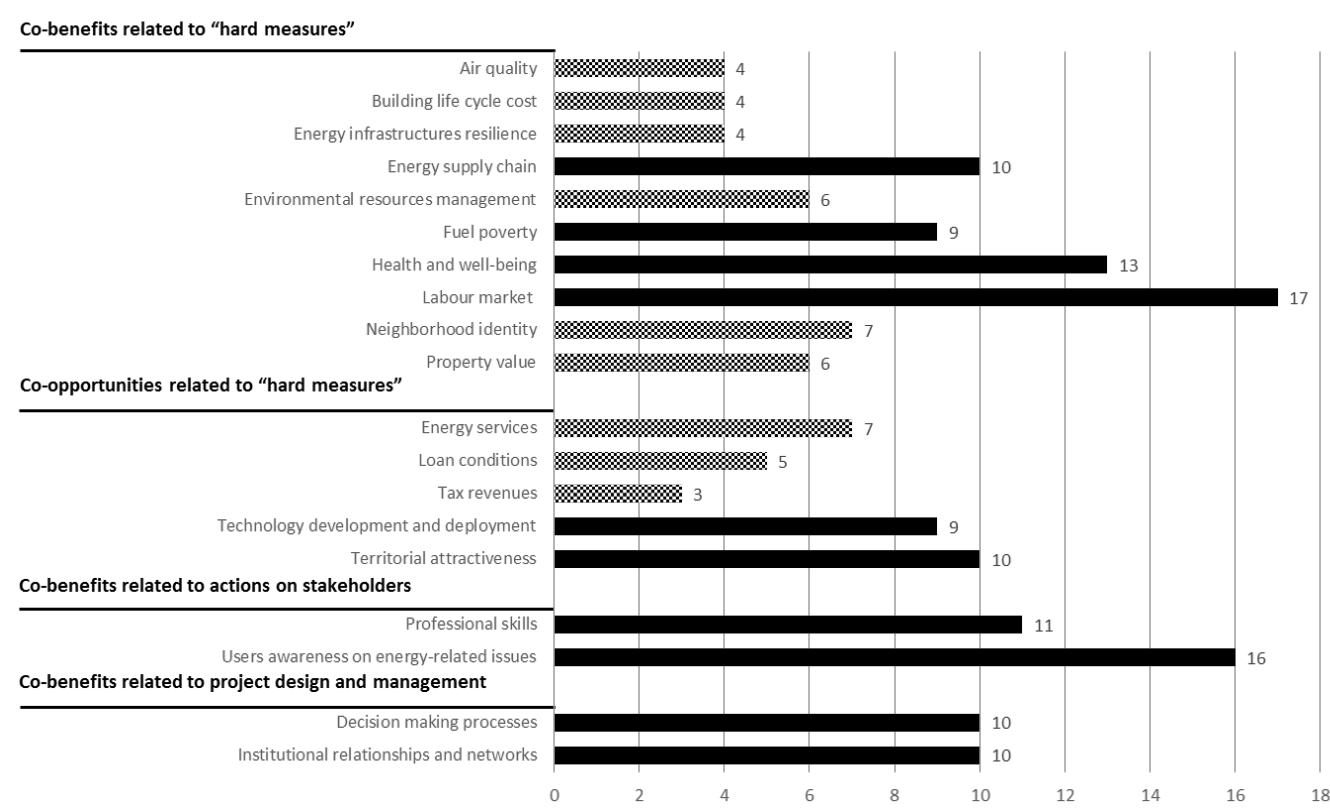

Figure 1: Co-benefits and co-opportunities identified in EU projects dealing with smart and sustainable districts. Source: (Bisello, 2017)

This new investigation focuses, as said before, on 12 SCC projects which have been financed between the year 2014 and 2017, involving 36 Lighthouse cities and 42 Follower cities, as shown in fig. 2.

The most exploited countries are Spain (6 Lighthouse cities out of 10 involved cities), United Kingdom ( 5 Lighthouse cities out of 7 involved cities), Germany (4 Lighthouse cities out of 6 involved cities), Italy (3 Lighthouse cities out of 6 involved cities), and France (3 Lighthouse cities out of 4 involved cities). This set of projects will have a total cost of 309M€, covered at $85 \%$ by the European commissions' contribution (260M€). Each one on average will benefit from $22 \mathrm{M} €$, will last 4-5 years, and some of these projects will unlock up to 20 times more in investment (European Commission, 2018a). 


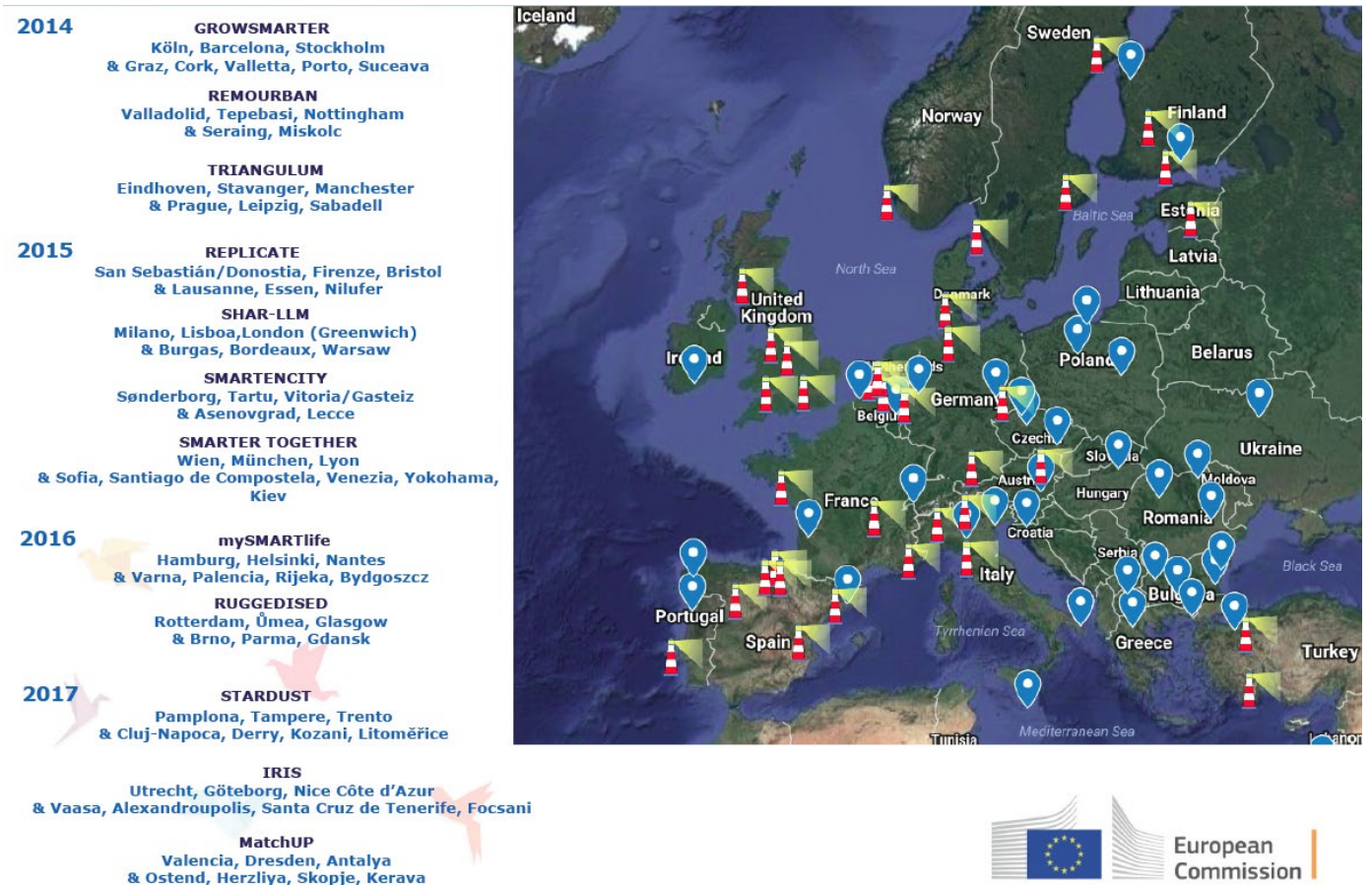

Figure 2: EU Lighthouse and Follower cities (SCC calls 2014-2017). Source: Bartholmes (2017)

\section{Multiple benefits investigation approach}

\subsection{On-line investigation}

This section explains the general methodology applied to co-benefits / multiple benefits investigation and details the steps proceed from raw information collection to a reasoned discussion. The following table 1 lists the investigated projects by funding call, providing the acronym, main financial figures and the link to the official website.

Table 1: SCC projects under the calls 2014-2017. Source: SCIS

\begin{tabular}{|c|c|c|c|c|c|}
\hline & Project name & $\begin{array}{l}\text { Year of } \\
\text { the Call }\end{array}$ & $\begin{array}{l}\text { Project Total } \\
\text { Cost (€) }\end{array}$ & $\begin{array}{c}\text { Project EC } \\
\text { Contribution }(€)\end{array}$ & Website \\
\hline 1. & GrowSmarter & 2014 & $34,635,913$ & $24,820,974$ & www.grow-smarter.eu/ \\
\hline 2. & REMOURBAN & 2014 & $23,791,530$ & $21,541,949$ & www.remourban.eu \\
\hline 3. & Triangulum & 2014 & $29,501,431$ & $25,420,602$ & https://www.triangulum-project.eu/ \\
\hline 4. & REPLICATE & 2015 & $29,250,564$ & $24,965,263$ & https://replicate-project.eu/ \\
\hline 5. & SHAR-LLM & 2015 & $28,068,094$ & $24,753,945$ & www.sharingcities.eu \\
\hline 6. & SmartEnCity & 2015 & $32,201,606$ & $27,890,139$ & https://smartencity.eu \\
\hline 7. & SMARTER TOGETHER & 2015 & $29,119,448$ & $24,742,979$ & https://www.smarter-together.eu \\
\hline 8. & MYSMARTLIFE & 2016 & $21,724,075$ & $18,656,102$ & https://www.mysmartlife.eu \\
\hline 9. & RUGGEDISED & 2016 & $19,562,868$ & $17,692,858$ & $\underline{\text { www.ruggedised.eu }}$ \\
\hline 10. & IRIS & 2017 & $20,704,013$ & $17,996,569$ & https://irissmartcities.eu/ \\
\hline 11. & MAtchUP & 2017 & $19,472,388$ & $17,418,339$ & http://www.matchup-project.eu/ \\
\hline 12. & STARDUST & 2017 & $21,093,539$ & $17,939,999$ & http://stardustproject.eu/ \\
\hline
\end{tabular}

The research method used is rooted in empirical case analysis and literature research. An online investigation will be undertaken, based on open-access sources representing the official point of view of project consortia (i.e. official websites of the projects) complemented by the official online repository developed by the EIP-SCC, the so-called Smart City Information 
Systems (SCIS, 2018). We expect to find explicit references to multiple benefits, different from pure energy benefits, as they are already mentioned in some project abstracts (see SCIS):

- GrowSmarter aims to improve the quality of life [...] while improving the citizens economy by lower energy costs and creating as much as 1500 new jobs (on the demonstration level).

- REPLICATE considers also the complexity of cities, the tangible benefits for citizens;

- SmartEnCity's [will] enable further benefits and secure involvement of citizens;

- SMARTER TOGETHER's [...] Expected results are: [...] 1400 created jobs, $130 \mathrm{M€}$ investments;

- The RUGGEDISED project [...]. The overall aims are: 1. Improving the quality of life of the citizens, by offering the citizens a clean, safe, attractive, inclusive and affordable living environment. [...] 3. Creating a stimulating environment for sustainable economic development, by generating more sustainable jobs, stimulating community involvement in smart solutions and to boost start-up and existing companies to exploit the opportunities of the green digital economy and Internet of Things

- The core idea of the STARDUST project is the demonstration of different "innovation islands" as urban incubators of technological, social, regulatory and market solutions

Exploring the project's website will give access to all the official and public available reports and materials produced, allowing a deeper investigation through a qualitative approach or text data mining

\subsection{Text data mining}

Text data mining, or text analytics, is the process of deriving high-quality information from text, typically derived through the devising of patterns and trends through means such as statistical pattern learning. Such process will allow passing from the raw data (e.g. the simple recurrence of the word co-benefits / multiple benefits or explicit mentioning of a precise benefit, as job increase, air quality, property value, etc.) to a specific classification of closelyrelated statements. This kind of research focuses on the qualitative and quantitative analysis of report contents giving a measure and a meaning of texts. For this purpose software like

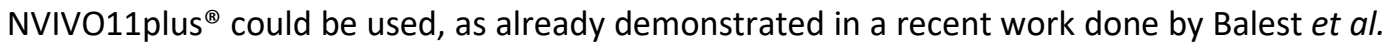
(2018) looking at the main dimensions and aspects of territory that can address its change towards energy transition.

\section{Conclusions and further steps.}

EU smart city projects are of particular interest due to their large geographical coverage and at the same time similar basic principles. Because of the recurrent funding scheme, structure, and size of consortia composition, they synthesize the findings and expectations of a large population of stakeholders, ranging from researchers to local officers and technicians, and from practitioners to decision makers or NGOs. Therefore, they offer an 
interesting overview of the society on the multiple benefits expected from the urban energy transition.

Content analysis of the selected publications will uncover recurrent statements in which the co-benefits / multiple benefits expected from each smart city project are cited, furthermore, this new investigation will allow a comparison of results with those reported in Bisello (2017) about the recurrence of co-benefits.

This will build up the knowledge baseline on with analyzing the assessment methodologies, qualitative and quantitative impacts, cascade effects, and interlinkages among co-benefits / multiple benefits of EU smart city projects for the definition of innovative and comparable Key Performance Indicators (KPIs).

The proposed approach is replicable in assessing other smart city projects outside the EU, which promote a sustainable and smart urban energy transition.

\section{References}

Balest, J. et al. (2018) 'Local reflections on low-carbon energy systems: A systematic review of actors, processes, and networks of local societies', Energy Research and Social Science. Elsevier, 42(January), pp. 170-181. doi: 10.1016/j.erss.2018.03.006.

Bartholmes, J. (2017) H2020 workprograme - SCC 2018. Brussels: Presentation given on 24th October 2017 at EC infoday.

Bisello, A. et al. (2017) 'Co-benefits of Smart and Sustainable Energy District Projects: an Overview on Economic Assessment Methodologies', Green Energy and Technology. Springer, pp. 127-164. doi: 10.1007/978-3-319-44899-2_9.

Bisello, A. (2017) Smart and sustainable projects at the energy-district level. How to assess them based on the co-benefits paradigm. University of Padova: Ph.D thesis.

Bisello, A. and Vettorato, D. (2018) 'Multiple Benefits of Smart Urban Energy Transition', in Droege, P. (ed.) Urban Energy Transition. second edi. Elsevier, pp. 467-490. doi: 10.1016/B978-008-102074-6.00037-1.

European Commission (2016) Clean Energy For All Europeans. Available at: https://ec.europa.eu/energy/en/topics/energy-strategy-and-energy-union/clean-energy-alleuropeans (Accessed: 5 July 2018).

European Commission (2018a) European Strategic Energy Technology Plan. doi: 10.2777/293881 KI-07-17-197-EN-C.

European Commission (2018b) Funding \& tender opportunities - Call ID: H2020-LC-SC3-20182019-2020. Available at: https://ec.europa.eu/info/fundingtenders/opportunities/portal/screen/opportunities/topic-details/lc-sc3-scc-1-2018-2019-2020 (Accessed: 5 July 2018).

Pol, O. and Lippert, L. (2010) CONCERTO. Overall energy performance of the 26 communities. Executive summary. Vienna: Österreichisches Forschungs- und Prüfzentrum Arsenal GesmbH.

SCIS (2018) Home I Smart Cities Information System. Available at: http://smartcitiesinfosystem.eu/ (Accessed: 5 July 2018).

Ürge-Vorsatz, D. et al. (2016) 'Measuring multiple impacts of low-carbon energy options in a green economy context', Applied Energy, 179, pp. 1409-1426. doi: 10.1016/j.apenergy.2016.07.027.

Zambotti, S., Pezzutto, S. and Bisello, A. (2019) Multiple-benefits from buildings' refurbishment: 
Evidence from smart city projects in Europe, Smart Innovation, Systems and Technologies. doi: 10.1007/978-3-319-92099-3_19. 